\title{
Ascariasis biliar con coledocolitiasis: una resolución con colangiopancreatografía retrógrada endoscópica. Reporte de un caso
}

\author{
Diana de Oliveira, Yhonny Castillo, Gabriela Lombardo y Ma. Fernanda Vilera* \\ Unidad de Gastroenterología, Policlínica de Barquisimeto Espíritu Santo, Estado Lara, Venezuela
}

\begin{abstract}
Resumen
Ascaris lumbricoides es un nematodo que causa enfermedades gastrointestinales, con una mayor prevalencia en los países en desarrollo y en niños. La ascariasis biliar es más común en adultos, su prevalencia se asocia con condiciones sanitarias deficientes y condiciones húmedas del suelo. Se presenta el caso de una paciente femenina de 34 años, con antecedentes de coledocolitiasis resuelta por colangiopancreatografía retrógrada endoscópica (CPRE), quien presentó dolor en hipocondrio derecho de un mes de evolución. Los exámenes de laboratorio reportaron alteración en las pruebas de funcionamiento hepático. La imagen fluoroscópica reveló una dilatación del colédoco $(14.3 \mathrm{~mm})$ y dilatación del conducto hepático izquierdo, con múltiples imágenes radiolúcidas aglomeradas en la porción proximal, consistentes con coledocolitiasis; también se notó la presencia de una imagen radiolúcida alargada y móvil consistente con un verme. Se realizó una nueva CPRE, utilizando la cesta de Dormia para la extracción del lito, que también capturó al verme.
\end{abstract}

Palabras clave: Ascaris lumbricoides. Coledocolitiasis. Colangiopancreatografía retrógrada endoscópica.

\section{Biliary ascariasis with choledocolitiasis: an endoscopic retrograde cholangiopancreatography resolution. Case report}

\begin{abstract}
Ascaris lumbricoides is a nematode that causes gastrointestinal diseases, with a higher prevalence in developing countries and in children. Biliary ascariasis is more common in adults, its prevalence is associated with poor sanitary conditions and humid soil conditions. We present the case of a 34-year-old female patient, with a history of choledocholithiasis resolved by retrograde endoscopic cholangiopancreatography (ERCP), who presented right hypochondrium pain of 1 month of evolution. Laboratory tests reported abnormal liver function tests. The fluoroscopic image revealed a choledochal dilation (14.3 mm) and left hepatic duct dilation, with multiple radiolucent images agglomerated in the proximal portion, consistent with choledocholithiasis; it was also noticed the presence of an elongated and motile radiolucent image consistent with a worm. $A$ new ERCP was made, using the Dormia basket for the extraction of the stone, which also captured the worm.
\end{abstract}

Key words: Ascaris lumbricoides. Choledocholithiasis. Cholangiopancreatography endoscopic retrograde.

\section{Correspondencia:}

*Ma. Fernanda Vilera

E-mail: mfvilera @ hotmail.com
Fecha de recepción: 28-05-2020

Fecha de aceptación: 20-07-2020 DOI: 10.24875 /END.20000045
Disponible en internet: 10-09-2020 Endoscopia. 2020;32(3):108-110 www.endoscopia-ameg.com 


\section{Introducción}

Ascaris lumbricoides es un nematodo que causa enfermedades gastrointestinales con una mayor prevalencia en los países en desarrollo y en niños ${ }^{1}$. En algunos casos pueden ingresar a través de la ampolla de Vater y ascender hacia el árbol biliar, siendo una causa rara de ictericia obstructiva ${ }^{1,2}$.

Se describe un caso de extracción del verme por colangiopancreatografía retrógrada endoscópica (CPRE).

\section{Caso clínico}

Mujer de 34 años con antecedente de coledocolitiasis resuelta mediante CPRE hace cinco años, quien presenta dolor en hipocondrio derecho de un mes de evolución; concomitantemente presenta disminución del apetito, sin fiebre ni vómitos. Al examen físico presenta dolor a la palpación superficial y profunda en hipocondrio derecho. Los exámenes de laboratorio revelaron elevación de aspartato aminotransferasa $102 \mathrm{U} / \mathrm{l}$, alanina aminotransferasa $94 \mathrm{U} / \mathrm{l}$, bilirrubina $(2.1 \mathrm{mg} / \mathrm{dl})$ y leucocitosis de 13,700 con neutrofilia. El ultrasonido reportó moderada dilatación del conducto colédoco. Se realizó una nueva CPRE con fluoroscopia, donde se evidenciaron imágenes del colédoco dilatado $(14.3 \mathrm{~mm})$ y dilatación del conducto hepático izquierdo; con múltiples imágenes radiolúcidas aglomeradas en la porción proximal del colédoco, consistente con coledocolitiasis; también se evidenció la presencia de una imagen radiolúcida alargada y móvil, consistente con un verme (Fig. 1A). Se procedió a utilizar la cesta de Dormia para la extracción del lito, la cual también capturó al verme durante la extracción (Fig. 1B). Se indicó albendazol $400 \mathrm{mg}$ vía oral/día durante tres días consecutivos. La paciente evolucionó sin complicaciones.

\section{Discusión}

La ascariasis es una de las enfermedades helmínticas más comunes, afecta aproximadamente a 1.4 billones de personas en el mundo ${ }^{3,4}$ y en los países tropicales de África, América y Asia del Este se observa la mayor prevalencia (45-95\%) $)^{1,3}$. En la forma biliar, la irritación causada por el parásito produce cólico biliar y espasmo del esfínter de Oddi, con obstrucción biliar parcial que puede conducir a complicaciones como necrosis del conducto, calcificación, litiasis, estenosis, fibrosis o colangitis ${ }^{5}$.

Antecedentes de colecistectomía, esfinterotomía, coledocostomía o esfinteroplastia son considerados un factor de riesgo debido a factores fisiológicos, bioquímicos y mecánicos que facilitan la migración de las lombrices después de estos procedimientos, los cuales incluyen la dilatación del conducto biliar común y el aumento de colecistoquinina ${ }^{1}$. Se ha reportado la ascariasis biliar como complicación de la esfinterotomía endoscópica en un $1.4 \%^{4}$, esta generalmente ocurre días o semanas después del procedimiento, especialmente en algunas regiones donde la ascariasis es epidémica ${ }^{6}$. En este caso, la paciente tenía un antecedente de CPRE remoto, puesto que fue hace cinco años, y procedía de una zona rural donde existe elevada prevalencia de ascariasis, lo que, sumado a la disrupción previa de una barrera mecánica, facilitan la migración del parásito.

El ultrasonido es el estudio de elección para el diagnóstico por su sensibilidad, especificidad y por no ser invasivo $^{1,3,5}$, sin embargo los hallazgos dependen de la ubicación del verme al momento, por lo que el diagnóstico no se realiza en hasta en un $50 \%$ de las ocasiones $^{3}$. La primera línea de tratamiento está constituida por fármacos antihelmínticos, no obstante su uso es controvertido debido a su baja absorción intestinal y escasa excreción biliar; además, puede desencadenar la migración de otro nematodo a la vía biliar, su muerte la posible obstrucción mecánica del ducto o su consecuente maceración puede originar una respuesta inflamatoria que lleve a la estenosis de la vía ${ }^{5,7}$. Si bien la eficacia está relacionada al retorno del verme al duodeno, se espera la resolución de los síntomas en un $68-80 \%$ de los $\operatorname{casos}^{1,8}$. El tratamiento endoscópico está reservado para la respuesta farmacológica inadecuada, los resultados están asociados al entorpecido acceso hasta el nematodo, no obstante su eficacia ha sido reportada en un $75 \%$ de los $\operatorname{casos}^{8}$. Por último, la cirugía representa una alternativa en aquellos casos donde el tratamiento farmacológico y endoscópico ha fracasado. En nuestro paciente se debió utilizar la CPRE, puesto que además presentaba coledocolitiasis; el uso de albendazol fue indicado como terapia complementaria por su excreción principalmente biliar.

\section{Financiamiento}

La presente investigación no ha recibido ayudas específicas provenientes de agencias del sector público, sector comercial o entidades sin ánimo de lucro.

\section{Conflicto de intereses}

Los autores declaran no tener conflicto de intereses. 


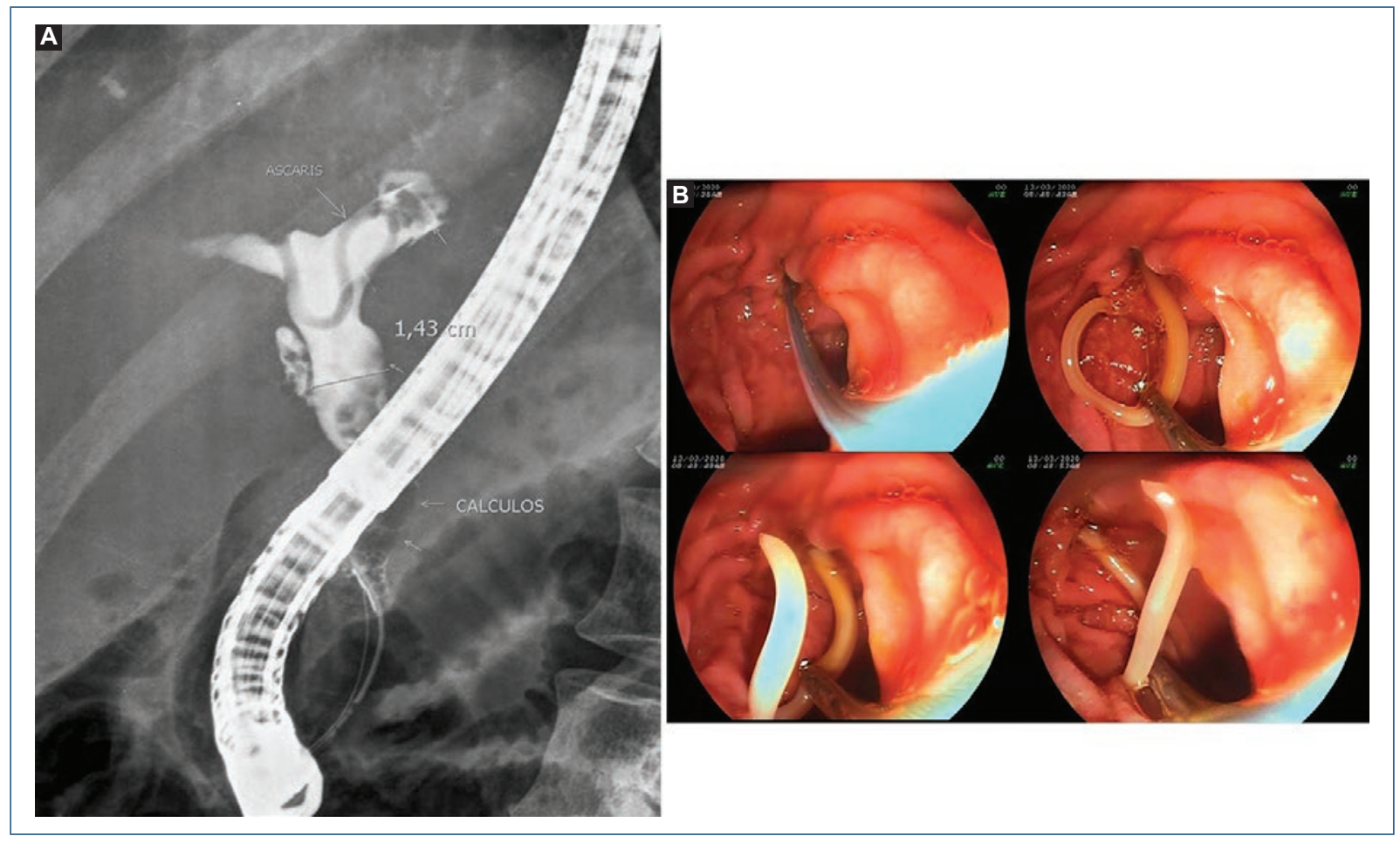

Figura 1. A: colangiopancreatografía retrógrada endoscópica (CPRE) donde se evidencia colédoco dilatado (14.3 mm) con presencia de múltiples cálculos en porción proximal y verme en porción distal. B: extracción de verme por medio de CPRE.

\section{Responsabilidades éticas}

Protección de personas y animales. Los autores declaran que para esta investigación no se han realizado experimentos en seres humanos ni en animales.

Confidencialidad de los datos. Los autores declaran que han seguido los protocolos de su centro de trabajo sobre la publicación de datos de pacientes.

Derecho a la privacidad y consentimiento informado. Los autores han obtenido el consentimiento informado de los pacientes y/o sujetos referidos en el artículo.

\section{Bibliografía}

1. Shah OJ, Zargar SA, Robbani I. Biliary ascariasis: A review. World J Surg. 2006;30:1500-6.

2. Fuente-Lira Mdl, Molotla-Xolalpa C, Rocha-Guevara ER. Ascariasis biliar. Informe de un caso y revisión en la literatura. Cir Ciruj. 2006;74:195-8.

3. Das A. Hepatic and biliary ascariasis. J Glob Infect Dis. 2014;6(2):65-72.

4. Gupta R, Agarwal DK, Choudhuri GD, Saraswat VA, Baijal SS. Biliary ascariasis complicating endoscopic sphincterotomy for choledocholithiasis in India. J Gastroenterol Hepatol. 1998;13(10):1072-3.

5. Yepes NL, Sanín E, Sepúlveda ME. Ascaridiasis biliar: manejo endoscópico. Rev Col Gastroenterol. 2003:18:83-7.

6. Wang J, Pan YL, Xie Y, Wu KC, Guo XG. Biliary ascariasis in a bile duct stones-removed female patient. World J Gastroenterol. 2013;19:6122-4.

7. Sanai FM, Al-Karawi MA. Biliary ascariasis: Report of a complicated case and literature review. Saudi J Gastroenterol. 2007;13:25-32.

8. Beckingham IJ, Cullis SN, Krige JE, Bornman PC, Terblanche J. Management of hepatobiliary and pancreatic Ascaris infestation in adults after failed medical treatment. Br J Surg. 1998;85(7):907-10. 